\title{
REFORMULANDO LAS IMÁGENES DEL PODER EN TORNO A LA DOMESTICIDAD. LA EDUCACIÓN FORMAL E INFORMAL COMO BASE DE LA CIUDADANÍA FEMENINA*
}

\author{
LUZ SANFELIU \\ Universitat de València
}

Recibido: 31/10/2010

Aceptado: 12/11/2010

\section{Resumen}

Durante la revolución liberal española, la atribución de competencias femeninas en el ámbito de lo doméstico comportó la implementación de una educación diferencial en función del género y ralentizó la incorporación de las niñas en el sistema escolar. Desde esta perspectiva, el presente artículo se propone relacionar los discursos y prácticas de los distintos feminismos hispanos, de la Institución Libre de Enseñanza o del republicanismo respecto a la educación de las mujeres, con las doctrinas institucionales, las legislaciones y las nuevas doctrinas pedagógicas. El objetivo es dar cuenta de la forma en que estos sectores alternativos cuestionaron las normas del poder, modificaron las políticas estatales e hicieron posible el acceso de las niñas y mujeres a la educación y a una ciudadanía en mayor medida igualitaria.

Palabras clave: Historia de la educación de las mujeres, ciudadanía femenina, identidades, derechos, coeducación.

\footnotetext{
* Este trabajo participa del Proyecto I+D+I HAR2008-03970/HIST, del Ministerio de Ciencia e Innovación.
} 


\begin{abstract}
During the Spanish liberal revolution, the attribution of female competences in the domestic area led to the implementation of a differential education in function of the gender and slowed down the incorporation of girls into the schooling system. Based on this perspective, the aim of this article is to associate the discourses and practices of the different Hispanic feminisms, of the Free Teaching Institution or of republicanism with respect to the education of women, with institutional doctrines, legislations and new pedagogical doctrines. The aim is to inform about how these alternative sectors questioned the rules of power, modified the state policies and made it possible for girls and women to have a more equal access to education and to citizenship.
\end{abstract}

Keywords: History of the education of women, identities, rights, pedagogy, co-education. 


\section{Introducción}

Durante la revolución liberal española los sistemas escolares se convirtieron en instrumentos de instrucción primaria universal y también en agentes de difusión de los valores que debían contribuir a la integración de la sociedad en torno a un imaginario nacional común. Las reflexiones de Benedict Anderson sobre los elementos discursivos y materiales que constituyeron la «Comunidad Imaginada» apuntan en este sentido al señalar que la escuela, el ejército o las redes de la comunicación introdujeron en Europa Occidental la idea nacional entre la población. ${ }^{1}$ Mediante instrumentos coercitivos como el ejército, o simulados como la educación nacional, los nuevos aparatos estatales fabricaron la propia nación y nacionalizaron progresivamente la sociedad. ${ }^{2}$

También los discursos que difundieron los partidos, la prensa doctrinaria o las prácticas de la educación popular a través de la sociabilidad política, ${ }^{3}$ constituyeron factores de primer orden para que los hombres se formaran en los preceptos y normas de la sociedad liberal y posteriormente democrática y en el aprendizaje formal e informal de las reglas del derecho de representación, sinónimo de la nueva libertad y autonomía del individuo varón. Los nuevos lenguajes configuraron nuevas identidades masculinas, fundamentadas en la conciencia de la igualdad política, a pesar de la inicial exclusión de los no propietarios del sufragio universal o de las particularidades de clase.

En suma, la propia escuela o instancias ajenas a ella recurrieron a estrategias como la inclusión de la educación cívica entre los contenidos de la enseñanza, al uso de catecismos políticos, y a la creación de una serie de lenguajes,

1. ANDERSON Benedict. Comunidades imaginadas. Reflexiones sobre el origen y la difusión del nacionalismo. México, Fondo de Cultura Económica, 1993.

2. HовSBAWM, Eric. La era del capitalismo (1848-1875). Madrid, Guadarrama, 1977, pp. 123-146.

3. Véase al respecto GUEREÑA, Jean-Louis (coord). Monografía: La educación popular en los siglos XIX y XX. Historia de la Educación, 20 (2001), pp. 5-188.

Feminismo/s 16, diciembre 2010, pp. 83-105 
símbolos y fiestas nacionales que contribuyeron a este proceso tanto en lo escolar como en lo extraescolar. ${ }^{4}$

Siguiendo los análisis de Michel Foucault, en cada contexto histórico «el poder» define a través de discursos institucionales, normas, valores, etc., verdades que deben ser incorporadas a la sociedad. Para lograr este objetivo quienes conforman dicha sociedad son subjetivizados por los discursos dominantes, los discursos del saber y del poder. ${ }^{5}$

Por tanto, las nociones claves que sustentaban las prácticas de la ciudadanía se debieron «enseñar» a los niños y a los hombres en un proceso de larga duración que, incluyendo la escuela y la educación política informal, tenía por finalidad construir con efectos de poder la identidad del ciudadano varón, rector de la vida pública, sujeto real o potencial de derechos y deberes, receptor y garante de la soberanía nacional.

En el caso de las mujeres, su inclusión en las instituciones escolares y su formación en los valores y en las normas de la nueva ciudadanía, lejos de constituir una unidad relacionada y complementaria, como fue el caso de los hombres, se reveló desde sus orígenes como un proceso complejo y paradójico. Como ha puesto de relieve la teoría crítica feminista, la construcción genérica de la dicotomía privado-público afianzó un concepto de ciudadanía que a la vez que proclamaba la igualdad de quienes formaban la nación, negaba a las mujeres dicha igualdad y los derechos civiles y políticos que ésta comportaba. ${ }^{6}$ Los discursos legislativos y pedagógicos de los nuevos estadosnación se apoyaron en los argumentos ilustrados y en la filosofía romántica para establecer y naturalizar la diferencia sexual y la complementariedad jerarquizada de los roles de género. La atribución de las competencias femeninas en el ámbito de lo doméstico, finalmente, comportó la implementación de una educación diferencial en función del género y ralentizó la incorporación de las niñas a la escolarización. Además, la formación de las mujeres en las normas y en los valores de la ciudadanía dejaba de tener sentido en la medida en que el espacio socialmente atribuido a la feminidad correspondía al ámbito privado y el sujeto real o potencial de derechos era el varón.

4. OsSEnBACH SAUter, Gabriela. «Génesis de los sistemas educativos nacionales en el Mundo Occidental». En A. Tiana Ferrer [et. al] (coords). Historia de la Educación. Edad Contemporánea. Madrid, 2002, UNED, p. 29.

5. Foucault, Michel. «El sujeto y el poder». En H. Dreyfus y P. Rabinisu (coord.), Michel Foucault: más allá del estructuralismo y la hermenéutica. México, Universidad de México, 1988, p. 227.

6. CABRERA BOCH, Isabel. «Ciudadanía y género en el liberalismo decimonónico español». En P. Pérez Cantó (ed.). También somos ciudadanas. Madrid, Universidad Autónoma de Madrid, 2000, pp. 171-214. 
Sin embargo, la normalización de la diferencia sexual no fue en la etapa contemporánea una cuestión cerrada. Investigaciones recientes destacan los debates y las discusiones sociales que trataron de reformular desde distintas culturas políticas las identidades femeninas y el papel activo de los feminismos hispanos en la construcción de una ciudadanía igualitaria. ${ }^{7}$

Por esta razón, el presente artículo se propone indagar en el acceso de las mujeres a la ciudadanía, interrelacionando la evolución de los discursos y prácticas en torno a la educación femenina de diversos grupos sociales: moderantismo, proto-feminismo, feminismos de corte progresista, sectores institucionistas o republicanos, con las doctrinas y prácticas institucionales, legislativas, políticas y pedagógicas en el ámbito socio-educativo. Siguiendo la perspectiva metodológica de Joan Scott, el objeto de los análisis históricos son las interrelaciones entre distintas dimensiones. Las dimensiones simbólicas, como mitos socialmente construidos, no son ajenas a las dimensiones normativas y sistémicas, donde las actividades y organizaciones sociales y las representaciones culturales dan forma a las dimensiones subjetivas y construyen las identidades de género. ${ }^{8}$ También para la citada historiadora, el género es una forma primaria de relaciones significantes de poder y los cambios en la organización de las relaciones sociales corresponden siempre a cambios en la representación del poder. De hecho, las declaraciones normativas dependen del rechazo o de la representación de posibilidades alternativas y a veces tienen lugar disputas abiertas sobre las mismas. ${ }^{9}$

A partir del Sexenio democrático, las retóricas y actuaciones de los feminismos, junto a la labor de algunos sectores de la Institución Libre de Enseñanza o del republicanismo, representaron posibilidades alternativas a los discursos hegemónicos en torno a la feminidad. Con sus demandas de instrucción o con la puesta en marcha de asociaciones feministas o plataformas educativas y escolares autónomas ampliaron las atribuciones de las mujeres e implicaron al Estado y a otros grupos sociales en la tarea de implementar medidas que las preparasen en el ámbito educativo, profesional y cívico. En última instancia, fueron paulatinamente difundiendo y materializando nuevas identidades femeninas que reformulaban el arquetipo doméstico. Con ello, consolidaron cambios en las representaciones del poder que incluían

7. Aguado, Ana (coord.). Dossier Culturas Políticas y Feminismos. Historia Social. 67 (2010), pp. 69-173.

8. SCOTT, Joan W. «El género; una categoría útil para el análisis histórico». En J. S. Amelang y M. Nash (eds.). Historia y Género: Las mujeres en la Europa Moderna y Contemporánea. Valencia, Alfons el Magnànim, 1990, p. 44.

9. Ibíd., pp. 45-46.

Feminismo/s 16, diciembre 2010, pp. 83-105 
la posibilidad de que las mujeres accedieran a la educación, a profesiones liberales, se integraran progresivamente en la política y obtuvieran derechos y libertades equivalentes a los de los varones.

Como afirman también los enfoques foucaultianos, los sujetos sociales están inmersos en relaciones de producción y significación discursivas que suponen relaciones de poder. Dichas relaciones de poder están abiertas a juegos de resistencias múltiples. ${ }^{10}$ Estos nuevos discursos y prácticas de vida incorporaron paulatinamente a las mujeres a los espacios públicos y al reconocimiento de derechos verdaderamente universales, fueron por tanto «juegos de resistencias» que en última instancia posibilitaron la emergencia de identidades femeninas relacionadas con una ciudadanía plena.

\section{Cometidos domésticos y educación diferencial}

En el aspecto legislativo, los textos que fundamentaban en España el sistema público de educación nacional, universal para los varones, se hicieron reiteradamente eco de la visión social dicotómica respecto a los roles genéricos. La Comisión de Instrucción Pública de 1814 afirmaba en su Dictamen y Proyecto de Decreto sobre el arreglo general de la Enseñanza Pública que: «aquel sexo que forma parte preciosa de la sociedad» puesto que contribuía en gran manera a la «mejora de las costumbres y que se apodera[ba] casi exclusivamente de la educación del hombre», debía recibir una educación moral más que literaria y no tanto pública como doméstica y privada, puesto que las funciones sociales de las mujeres se concretaban en ser «buenas madres». ${ }^{11}$ Leyes posteriores, pese a los sucesivos cambios políticos e ideológicos que presidieron la primera mitad del siglo XIX, siguieron enfoques similares. ${ }^{12}$

Cuarenta años después, la Ley de Instrucción Pública de 1857, más conocida como Ley Moyano, que fue el punto de inicio de la educación pública para las chicas, seguía evidenciando las discriminaciones y la división de esferas. La creación de escuelas primarias o de Escuelas Normales que se prescribía como obligatoria para los niños y maestros, se acompañaba de meras recomendaciones y permisiones en las disposiciones referidas a niñas y maestras. También el currículo establecía fronteras simbólicas y prácticas en los planes de estudios ya que las asignaturas relacionadas con las «labores» presidían en

10. FouCAUlt, Michel. Historia de la sexualidad: la voluntad de saber, Madrid, Siglo XXI, 1976, p. 116.

11. Gil de Zárate, Antonio. De la Instrucción Pública en España, Colegio de Sordo-Mudos, 1855. (Edición facsímil, Pentalfa, Oviedo, 1995, tomo 1, pp. 85-86).

12. PALACIO LIS, Irene. «Mujeres aleccionando a mujeres. Discursos sobre la maternidad en el siglo XIX». Historia de la educación, 26 (2007), pp. 154-155. 
gran medida el proyecto de educación femenina. La Escuela pública seguía siendo el soporte legitimador de lo que se consideraba cultura doméstica, puesto que en la base de la educación no estaba el derecho de las mujeres a ser educadas, sino sus obligaciones establecidas en el espacio privado y en el ámbito de la maternidad. ${ }^{13}$

En la medida en que las concepciones de género estructuraban la implementación del sistema público de educación, las divisiones del trabajo social definían no solo los contenidos de la enseñanza, sino también el acceso real a los recursos de quienes debían impartir docencia o ser escolarizados. Por esas fechas, los resultados de las diferentes políticas nacionales en materia de escolarización revelan las brechas abiertas en el acceso a la escuela de ambos sexos. En 1855 estaban escolarizados en centros públicos de primaria el $69 \%$ de los niños frente al $31 \%$ de las niñas. ${ }^{14}$ En líneas generales, durante la primera mitad del siglo XIX el Estado no mostró un excesivo interés por la educación femenina. ${ }^{15}$

Junto a los discursos y a las prácticas legislativas estatales, lo pedagógico fue también reflejo de la mentalidad dominante de las clases burguesas, de su idea de Estado y de familia. Una mentalidad que se transmitía sin apenas fisuras a través de la segregación de los sexos y del currículo diferenciado que se impartía en la escuela pública. Los materiales que avalan estas afirmaciones son numerosos ${ }^{16}$ valga como muestra el texto escolar titulado El libro de oro de las niñas, que llegó a contar con 39 ediciones y se publicó desde 1860 hasta 1915. En él se afirmaba: «Lejos de mí la idea de dar a la mujer la misma educación escolástica que al hombre. Todo lo contrario, deberá enseñársele a ser mujer; previsora como la hormiga, laboriosa como la abeja $[\ldots] » .^{17}$

Si las retóricas institucionales en el ámbito educativo configuraban roles femeninos centrados básicamente en el hogar, también otros medios de educación informal como la prensa moderada contribuyeron paralelamente a difundir el mismo modelo hegemónico.

Como ha estudiado Inmaculada Jiménez, hasta el Sexenio democrático las revistas dedicadas específicamente a las mujeres se referían a cuestiones

13. Ballarín DOMingo, Pilar. La Educación de las mujeres en la España contemporánea (siglos XIX y XX. Madrid, Síntesis, 2001, pp. 42-43.

14. Ibid, pp. 42-43.

15. SARASÚA García, Carmen. «El acceso de niñas y niños a los recursos educativos de la España rural del siglo XIX». En J. M. Martínez Carrión (ed.). El nivel de vida en la España rural de los siglos XVII-XX. Alicante, Universidad de Alicante, 2002, pp. 415-463.

16. BALlaRín DOMINGO, Pilar. Op. cit., pp. 40-41.

17. Pirala, Antonio. El libro de oro de las niñas. Madrid, Establecimiento tipográfico de Mellado, 1860 p. 47. Citado por Ballarín Domingo, Pilar. Op. cit., p. 58.

Feminismo/s 16, diciembre 2010, pp. 83-105 
que incidían en la división de esferas y trataban materias insustanciales como las costumbres, los consejos domésticos, la moda o los salones como parte de las funciones femeninas. ${ }^{18}$ El tema educativo en estas publicaciones estaba enfocado a hacer reconocer a las mujeres su misión social y a ayudarlas a comprender su papel responsable como educadora de los hijos. La instrucción femenina pretendía conformar un modelo de feminidad virtuosa, provista de un barniz cultural que permitiera que «cuando lleg[ase] la ocasión de hablar en público [diese] pruebas de un talento bien cultivado». ${ }^{19}$ Otras cuestiones como la gestión de la política, del trabajo o del gobierno continuaban difundiéndose en sus páginas como ámbitos reservados exclusivamente a los varones.

Así pues, además de los modelos educativos, las revistas femeninas contribuyeron también a educar y dar forma al modelo identitario que se ha denominado el «Ángel del Hogar». Como auténticas «escuelas de papel», dichas revistas jugaron con la ventaja de su claro atractivo, lo que las convirtió en estímulo para el aprendizaje individual puesto que permitía un uso a la medida de las lectoras, uso que fue también social porque las lectoras de clase media encontraban en ellas referencias grupales con las que identificarse. ${ }^{20}$

En el período isabelino la subjetivización de las normas del poder no se agotaba en la distribución desigual de la posición de hombres y mujeres en el espacio educativo formal e informal. La dominación simbólica permitía además que una mayoría de mujeres «reconociera» los discursos hegemónicos en torno a la domesticidad, como «naturales» y evidentes y, por tanto, como no susceptibles de cuestionamiento o reformulación. ${ }^{21}$

La excepción a esta naturalización de las normas de género fueron los escritos de María Josefa Zapata y Margarita Pérez de Celis, que entre 1856 y 1866 publicaron en Cádiz El Pensil Gaditano, El Pensil de Iberia, El Nuevo Pensil de Iberia y El Pensil de Iberia y La Buena Nueva. Las propuestas vindicativas de las fourieristas gaditanas incorporaron la crítica al matrimonio como espacio de sujeción femenina, las exigencias de mejoras sociales y salariales

18. JiMÉNEZ MORELL, Inmaculada. La prensa femenina en España (desde sus orígenes a 1868). Madrid, De la Torre, 1992.

19. Jiménez Morell cita «La nueva redacción a sus suscriptores». El Defensor del Bello Sexo, 15 de marzo de 1845 (Ibíd., p. 68).

20. Las ideas corresponden al análisis de las revistas femeninas como material educativo. ReBOllo ESPINOSA, María José y NUÑEZ GiL, Marina. «Tradicionales, rebeldes, precursoras: instrucción y educación de las mujeres españolas a través de la prensa femenina (1900-1970)». Historia de la educación, 26 (2007), pp. 182-183.

21. Sobre la noción de violencia simbólica como normas que se imponen amparadas en su evidencia, véase Bourdieu, Pierre y PASSERON, Jean-Claude. La Réproduction: éléments pour une théorie du système d'enseignement. París, Les Editions de Minuit, 1970, p. 18. 
para las trabajadoras y la demanda de una educación para las mujeres que les permitiera acceder a la formación y a la cultura como un derecho propio. ${ }^{22}$

Ya en el Sexenio Democrático se introdujeron los ideales progresistas de la educación, sobre todo en lo referente a la libertad de enseñanza, aunque la legislación no presentó ningún avance respecto a las mujeres y a su instrucción en el sistema público. ${ }^{23}$

Hasta ese momento, la Iglesia había asegurado fundamentalmente la función docente en España. Antes los nuevos acontecimientos, las novedades políticas cuestionaron la educación que los estamentos eclesiásticos podían realizar en un nuevo Estado democrático fundado en la libertad. El proceso alcanzó también a las mujeres, y los hombres comenzaron a preguntarse por la cantidad y calidad de la instrucción que sus compañeras podían recibir y por el sentido social de sus conocimientos. ${ }^{24}$

También para los sectores afines al republicanismo, la educación femenina se convirtió, al menos a nivel teórico, en una preocupación importante para superar el atraso femenino y su dependencia de los estamentos clericales. La necesidad de que las mujeres fuesen instruidas se legitimaba en base a sus tareas como compañeras de los hombres y como educadoras de los hijos en los principios del progreso, el laicismo y la libertad, lo que confería una función política a los papeles femeninos, aun cuando les limitaba el ejercicio de la individualidad en un sentido pleno. ${ }^{25}$ Además, la llamada «cuestión femenina» pasó a ser difundida y analizada entre los grupos afines al republicanismo y al internacionalismo como parte de la «cuestión social», superando los anteriores e incuestionables designios de la naturaleza como motivo central de legitimación de las diferencias entre los sexos. De este modo la conformación discursiva de las identidades femeninas dejaron de depender exclusivamente de sus atribuciones domésticas construyéndose también en relación con los principios, valores, símbolos y rituales que manejaban diferentes fracciones o grupos políticos. ${ }^{26}$

22. EsPIgAdo, Gloria. «Las mujeres en el nuevo marco político». En I. Morant (dir.). Historia de las Mujeres en España y América Latina. Del siglo XIX a los umbrales del XX. Madrid, Cátedra, pp. 50-51.

23. SCANLON, Geraldine M. «La mujer y la instrucción pública: De la Ley Moyano a la II. ${ }^{a}$ República». Historia de la Educación, 6 (1987), pp. 195-196.

24. TURIN, Yvonne. La educación y la escuela en España de 1874 a 1902. Madrid, Aguilar, 1967 , p. 15.

25. SCANLON, Geraldine M. La polémica feminista en la España contemporánea (1868-1971). Madrid, Siglo XXI, 1976, p. 30.

26. SANFEliU, Luz. «Republicanismo y ciudadanía femenina en el Sexenio democrático». Bulletin d'histoire contemporaine de l'Espagne, 46 (2009). (En prensa).

Feminismo/s 16, diciembre 2010, pp. 83-105 
En las prácticas de vida, las actuaciones de las mujeres en los espacios de sociabilidad y en los actos públicos promovidos por el republicanismo fueron también más activas que en décadas anteriores y su presencia en estos círculos no fue nada despreciable. ${ }^{27}$ Feminidad y política comenzaron a ser realidades en menor medida excluyentes.

El valor otorgado a la presencia femenina en las filas republicanas se complementó con los elogios que la prensa de esta tendencia dedicaba a las mujeres que se asociaban y ocupaban las tribunas públicas. ${ }^{28}$ Así una serie de escritoras y oradoras abordaron desde estos nuevos espacios cuestiones de índole socio-política y también pusieron el acento en reivindicaciones tendentes a su propia emancipación. Por esas fechas, en torno a 1870, Narcisa de Paz Molins dirigió en Granada la Voz de la República promoviendo la liberación femenina y Elisa Huigon desde la revista Federación convocaba a otras republicanas y colectivistas a unirse para sacar a las mujeres de su «indiferencia y miserable situación». ${ }^{29}$ El tema educativo y profesional ocupó además una parte de los discursos de estas mujeres conscientes de su subordinación. Así, Magdalena Bonet i Fabregat, en la Escuela Democrática del Casino Republicano de Palma de Mallorca, se dirigía mayoritariamente a las mujeres haciendo referencia a la necesidad de que se emanciparan de la influencia clerical, pero destacaba asimismo el papel de las asignaturas científicas en la enseñanza femenina denunciando la falsa naturaleza atribuida a las mujeres por la autoridad masculina. ${ }^{30}$ Con similares intenciones se expresaba Carolina Pérez en un artículo publicado en La Ilustración Republicana Federal en 1872, donde afirmaba que las mujeres tenían derecho a pensar, a razonar y a opinar, tenían ideas de libertad y de emancipación. También debían contar con una sólida instrucción para poder desarrollar profesiones y gozar de autonomía económica como sucedía en Estados Unidos. ${ }^{31}$

Los círculos republicanos y obreros, y las primeras mujeres de estas formaciones que trataron de aliarse para promover su emancipación, al

27. De la Fuente Monge, Gregorio y SerRano García, Rafael. La revolución gloriosa. Un ensayo de regeneración nacional. Antología de textos. Madrid, Biblioteca Nueva, 2005, p. 19.

28. PeÑARRUBia, Isabel. Entre la ploma i la tribuna, Els orígens del primer feminisme a Mallorca, 1869-1890. Barcelona, Publicacions de l'Abadia de Montserrat, 2006, p. 111.

29. Huion, Elisa. "Carta de una obrera de Barcelona a La Federación». La Federación, 28 de julio de 1870 .

30. PeÑARRUBia, Isabel. Op. cit., pp. 99- 132.

31. PÉREZ, Carolina. «La mujer en la democracia», La ilustración Republicana Federal. Madrid, año II, 10 (28 de marzo de 1872), pp. 104-105. Citado en De LA FuENTE MonGe, Gregorio y SERRANO GarCía, Rafael. Op. cit., p. 19. 
cuestionar los discursos que naturalizaban su destino, abrieron una brecha en la violencia simbólica comúnmente aceptada que reducía por «evidentes» las atribuciones de las mujeres a los estrechos límites del hogar. En última instancia, estos discursos pioneros que hicieron de la instrucción un mecanismo de emancipación dieron nuevas posibilidades para las mujeres en el espacio social ya que al problematizar el sistema de normas, las identidades y experiencias femeninas pudieron ser paulatinamente reformuladas y modificadas.

\section{Reformas y demandas educativas en torno a las mujeres}

De forma paralela, otras mujeres liberales o cercanas a los círculos krausistas comenzaron también a editar revistas y ensayos cuya reclamación central fue la mejor preparación intelectual de la población femenina. Las obras de Concepción Arenal La mujer del provenir (1869) y La mujer de su casa (1883) o la de Sofía Tartilan Páginas para la educación popular fueron en su tiempo claras y contundentes denuncias de la educación tradicional de las mujeres. ${ }^{32}$ Asimismo, Concepción Gimeno de Flaquer, influida por el magisterio de Concepción Arenal, publicó en 1877 el ensayo titulado La mujer española. Estudios acerca de su educación y de sus facultades intelectuales. En dicho ensayo, se defendía que la instrucción era un derecho equiparable para ambos sexos. Desde 1872, había dirigido la revista La ilustración de la Mujer, editada en Barcelona, en la que se reivindicaba la educación física, moral e intelectual de las mujeres y se promovía el cambio de los modelos formativos conservadores. ${ }^{33}$ Otras revistas femeninas como El Parhtenón o La Ilustración de la Mujer, en Madrid, insistían de igual modo en reclamar una mejor preparación intelectual para la población femenina, en un contexto social en el que se agudizaban las polémicas en torno a la legitimidad de cursar carreras superiores que suscitaron las primeras universitarias españolas. ${ }^{34}$ El resultado de estas actuaciones fue que el incipiente movimiento proto-feminista asumió la vindicación como médula política básica de sus discursos, ya que la reivindicación educativa de estos sectores femeninos significó también deslegitimar de una forma sostenida el

32. SCANLON, Geraldine M. La polémica feminista... Op. cit. p. 22-23.

33. MARTineZ, Cándida [et al.] (dirs.). Mujeres en la Historia de España. Enciclopedia biográfica, Barcelona, Planeta, 2000, pp. 548- 551.

34. Rodriguéz SÁNCHEZ, Ma de los Ángeles. «Matilde Cherner y «La Ilustración de la Mujer»». En L.F. Díaz Larios. [et al.] (eds.). Lectora, Heroina, Autora (La mujer en la literatura española del siglo XIX). III Coloquio de la Sociedad de Literatura Española del Siglo XIX (Barcelona, 23-25 de octubre de 2002). Barcelona, 2005, pp. 307-319.

Feminismo/s 16, diciembre 2010, pp. 83-105 
sistema de dominio de los varones cuestionando las normas que negaban la igualdad intelectual de ambos sexos. ${ }^{35}$

Coincidiendo asimismo con los acontecimientos de 1868, se constituyó por iniciativa de Faustina Sáez de Melgar el foro de encuentro y discusión que organizó el «Ateneo Artístico y Literario de Señoras» y que posteriormente tendría su continuidad en la Institución para la Enseñanza de la Mujer. El Ateneo se propuso como foro de debate y discusión para las mujeres y como un espacio que daba posibilidades a la ampliación de sus horizontes educativos. Fernando de Castro, Rector de la Universidad de Madrid, conocido por su tendencia krausista, ofreció ayuda y respaldo a las señoras y, a partir del Ateneo, se pusieron en marcha las Conferencias dominicales para la Mujer. La vía de la instrucción auspiciada desde las Conferencias tenía como objetivo aplicar reformas educativas para el mejor cumplimiento de las funciones femeninas tradicionales en el ámbito familiar.

De forma temprana los objetivos de las Conferencias dominicales sobrepasaron el espacio privado y familiar y derivaron hacia una cierta cualificación profesional diseñada específicamente para las mujeres. La iniciativa siguiente de Fernando de Castro fue alentar en Madrid la constitución de una Escuela de Institutrices y en junio de 1871 una Asociación para la Enseñanza de la Mujer donde se impartían clases de Comercio. La propuesta se extendió pronto por todo el estado español llegando a Barcelona y Valencia en 1880, a Málaga en 1886, a Sevilla en 1888 y a Cádiz y Vitoria en 1892. En líneas generales, estas asociaciones facilitaron a un grupo minoritario de jóvenes una instrucción profesional de calidad, lo que multiplicó sus oportunidades laborales. También progresivamente la labor de sus miembros, tanto hombres como mujeres, consistió en reivindicar el derecho femenino al trabajo y al ejercicio de profesiones liberales. ${ }^{36}$

El proyecto de reforma de los krausistas se implementó principalmente de dos modos: por un lado a través de la creación de «centros piloto», como la Institución Libre de Enseñanza o las escuelas de la Asociación para la Enseñanza de la Mujer, y, por otro lado, a través de su influencia en las políticas pedagógicas oficiales para que se incorporaran sus ideales en la educación nacional. ${ }^{37}$

35. Celia Amorós establece que la vindicación feminista es un punto que va más allá que el anterior memorial de agravios puesto que la vindicación adoptó a lo largo del tiempo una dimensión deslegitimadora y política. Amorós, Celia. Tiempos de feminismo. Sobre feminismo, proyecto ilustrado y postmodernidad. Madrid, Cátedra, 1997, p. 56.

36. Di FEBO, Giuliana. «Orígenes del debate feminista en España. La Escuela krausista y la Institución Libre de Enseñanza (1870-1890)». Sistema, 12 (1976), pp. 49-82.

37. SCANLON, Geraldine M. La polémica feminista... Op. cit., p. 40. 
Así, durante los primeros años de la Restauración con los fusionistas de Sagasta en el poder, el ministro de Fomento José Luis Albareda, introdujo en 1882 una serie de reformas legislativas favorables a las mujeres de clara inspiración institucionista. Lo singular de la iniciativa, que duró algo más de dos años hasta la subida al poder de los conservadores, fue que por vez primera el Estado se responsabilizó de la cultura femenina y se planteó la cuestión del derecho de la mujer a una instrucción superior y profesional. En concreto, se les encomendaron las escuelas de párvulos y se creó un curso teórico-práctico para quienes aspiraban al mencionado magisterio. Se reformó también la Escuela Normal Central de Maestras y se amplió su programa, que llegó a contar con más de 16 asignaturas que incluían los ejercicios de gimnasia, la pintura industrial o el aprendizaje de idiomas vivos. Estas enseñanzas se consideraban el germen de escuelas propias a desarrollar en el futuro. El profesorado se preveía que pudiera ser mixto, pero sólo hasta que hubiera suficientes mujeres preparadas para desempeñar los puestos; se introdujo también el sistema cíclico de enseñanza y se creó un título. Además el gobierno dotó económicamente las reformas y la Escuela Normal Central tuvo un nuevo local y un material pedagógico impresionante. ${ }^{38}$

A lo largo del tiempo, los discursos y las actuaciones llevadas a cabo por los institucionistas, tanto hombres como mujeres, en la Escuela Normal Central de Maestras supondrían un impulso renovador en los métodos pedagógicos con los que se instruyeron durante décadas un gran número de jóvenes maestras que progresivamente gozaron de mayor reconocimiento social, profesional e institucional. ${ }^{39}$

De forma paralela, el gobierno liberal patrocinó en 1882 el Congreso Nacional Pedagógico celebrado en Madrid. En dicho Congreso se declaró la utilidad de la instrucción para preparar a las mujeres en sus papeles de esposas y madres, pero también se reconoció que era conveniente enseñarles oficios que les permitieran mantener a su familia en caso de necesidad. La Institución Libre de Enseñanza estuvo ampliamente representada. Maestras como Adela Riquelme y Encarnación Martínez hicieron oír sus voces demandando «a igual trabajo, igual salario» y defendiendo la misma aptitud de la mujeres para las tareas de la inteligencia. ${ }^{40}$

38. SCANLON, Geraldine M. «La mujer y la instrucción pública...» Op. cit., p. 206.

39. Saiz Otero, Concepción (C. Colmenar Orantes ed.). La revolución del 68 y la cultura femenina. Un episodio nacional que no escribió Pérez Galdós. Madrid, Biblioteca Nueva, 2006.

40. Ballarín Domingo, Pilar. Op.cit., p. 77.

Feminismo/s 16, diciembre 2010, pp. 83-105 
La extensión de las preocupaciones educativas se puso de manifiesto también en el Congreso Hispano Portugués Americano de 1892 que dedicó una sección a la educación de las mujeres. Con la participación de los institucionistas y de figuras femeninas relevantes como Concepción Arenal y Emilia Pardo Bazán, se hicieron manifiestos los tímidos cambios que se estaban operando en la sociedad española respecto a esta cuestión. La participación femenina en la organización fue activa, reflejando el abanico cada vez más amplio de mujeres que ocupaban posiciones profesionales: maestras, profesoras de escuela normal, directoras de colegios privados, escritoras, médicas y estudiantes universitarias. También, en medio de una viva polémica, se recogieron los principios igualitarios en la enseñanza de las mujeres, aunque su ejercicio profesional sólo fue aceptado en la esfera educativa. ${ }^{41}$

La asignación de nuevos significados a la problemática de la educación femenina estaba haciendo posible que un creciente número de grupos e instituciones se hiciera consciente de la existencia de un conflicto, identificara sus causas y aplicara medidas para resolverlo. A las nuevas instituciones educativas para las mujeres que se estaban creando, a los debates congresuales, a las revistas y ensayos femeninos que articulaban sus demandas en torno a este tema, se sumaron (provisionalmente) las actuaciones del gobierno, las reformas legislativas y la implicación del Estado como responsable principal de garantizar e impulsar la mejora educativa de la población femenina.

En suma, tanto en las políticas institucionales como desde distintos sectores sociales, las mujeres se comenzaron a concebir también como individuos y no sólo como parte de la sociedad conyugal. Individuos a los que había que dar una instrucción que las preparase intelectual y profesionalmente en campos como la educación, la industria y el comercio.

Sin embargo, los debates y las nuevas iniciativas que se estaban produciendo alcanzaron el siglo XX sin que se consiguiera una opinión unánime favorable a una educación igualitaria. Las posiciones más tradicionales seguían defendiendo que las niñas debían educarse en la familia más que en la escuela pública. La instrucción femenina seguía considerándose fuente de inmoralidad y pérdida de la feminidad. Además, para estos grupos, en mayor

41. Capel Martínez, Rosa $M^{a}$. «La apertura del horizonte cultural femenino: Fernando de Castro y los Congresos Pedagógicos del siglo XIX». En Mª́. Duran [et al.] (eds.). Mujeres y sociedad en España, 1700-1975. Madrid, Ministerio de Cultura, Instituto de la Mujer, 1986, pp. 128- 145. 
medida conservadores, la inferioridad natural de las mujeres indicaba que la educación no les era necesaria. ${ }^{42}$

Pese a ello, las cifras públicas de escolarización primaria revelan una lenta pero progresiva implicación del Estado en la escolarización de las niñas. En 1885 el porcentaje de niñas que se educaban en los centros públicos eran del $45 \%$ y el de los niños el $55 \% .{ }^{43}$ Pese a las tímidas mejoras alcanzadas en términos de equidad de género, el panorama general de la enseñanza en España seguía siendo desolador. ${ }^{44}$

En todo caso, el modelo reformista de los círculos institucionistas y su prioridad absoluta por llevar a cabo un cambio en profundidad de la educación nacional manifestaron también su preocupación por implementar prácticas pedagógicas, aunque fuese a pequeña escala, que incidieron en la igualdad. De hecho defendieron de forma pionera el principio de coeducación en la educación primaria y secundaria, es decir, la enseñanza de chicos y chicas en similares asignaturas y en las mismas aulas. ${ }^{45}$ Prueba de esta cierta equiparación, que en ningún caso cuestionaba las funciones domésticas y maternales de las mujeres, fue que ya a comienzos del siglo XX, la Junta de Ampliación de Estudios inspirada y gestionada por institucionistas, concedió becas de viajes al extranjero para el profesorado y el alumnado en rigurosa y precoz paridad. ${ }^{46}$

\section{Educación laica y racional y élites feministas}

El nuevo siglo suscitó una explosión de interés por las cuestiones pedagógicas y la crisis finisecular agudizó la urgencia por emprender reformas radicales en el campo educativo que impulsaran la regeneración de la nación. Ambas cuestiones beneficiarían a la educación de las mujeres. En las políticas estatales se consiguió la colaboración entre los partidos liberales y conservadores y se creó el Ministerio de Instrucción Pública y Bellas Artes. La influencia en las nuevas legislaciones de los institucionistas siguió incrementándose y el Real Decreto de Romanones de octubre de 1901 reformó los programas de primera enseñanza ampliando las asignaturas en el sentido de implementar una educación integral y, por primera vez, el programa no hizo distinción entre

42. Ballarín, Pilar. «La construcción de un modelo educativo de <<utilidad doméstica >>». En G. Fraisse y M. Perrot (dirs.). Historia de las mujeres. El siglo XIX. Madrid, Taurus, 1993, pp. 609-610.

43. Ballarín Domingo, Pilar. La Educación de las mujeres...Op.cit., pp. 40-41.

44. SCANLON, Geraldine M. «La mujer y la instrucción pública...» Op. cit., pp. 198-199.

45. Cuesta EsCudero, Pedro. La Escuela en la reestructuración de la Sociedad Española. 1900-1923. Madrid, Siglo XXI, 1994, p. 144.

46. Ballarín Domingo, Pilar. La Educación de las mujeres... Op. cit., p. 91.

Feminismo/s 16, diciembre 2010, pp. 83-105 
el curriculum masculino y femenino. Se aumentó también la edad escolar de seis a doce años haciendo obligatoria la asistencia a ambos sexos. ${ }^{47}$

En ese mismo contexto, tanto los republicanos blasquistas como los lerrouxistas, que contaban con una amplia base social de organizaciones obreras, continuaron ampliando el acceso de las mujeres a los espacios públicos en actos como mítines, manifestaciones, sociabilidad, ceremonias civiles y banquetes democráticos. La defensa de una vida familiar de corte laico y la preocupación más teórica que práctica en torno a la necesidad de una mayor instrucción femenina configuraron el ideal de mujer republicana activa y participativa en ciertos ámbitos de la política e interesada por la ciencia, la razón y el librepensamiento. Un modelo de identidad que, si bien siguió siendo dependiente de la autoridad masculina, posibilitó en mayor medida que las mujeres se instruyeran en carreras superiores, ejercieran profesiones y aumentaran su presencia e influencia en la vida pública. ${ }^{48}$

También estos círculos republicanos articularon un movimiento de escuelas laicas para hacer frente al predominio de la Iglesia y de las órdenes religiosas en la educación. La insuficiencia de la enseñanza oficial para atender a la población escolar actuaba como factor favorable a la expansión de tales iniciativas. La perspectiva pedagógica de dichas escuelas era científica, racionalista, laica y mixta en donde niños y niñas recibían educación e instrucción en igual grado, y estas últimas, además, en las labores y en los conocimientos peculiares de su sexo, según expresión de la época. El campo de la acción educativa no estatal se amplió con estas escuelas laicas y también con las escuelas racionalistas promovidas por los círculos anarquistas, añadiendo para las niñas nuevas y mayores posibilidades de recibir una instrucción primaria mixta, coeducativa y racional, vinculada estrechamente a los valores, las ideas y los ritos de las culturas políticas republicanas y anarquistas. ${ }^{49}$

En el mismo período y vinculadas al republicanismo hispano surgieron además la Asociación General Femenina en Valencia (1897-1910), la Sociedad Progresiva de Barcelona (1898-1920) con filiales en diversos puntos de Cataluña, la Unión Femenina del Librepensamiento en Huelva (1897-1906), la Sociedad de Mujeres Librepensadoras en Mahón (1899-?) y la Sociedad Progresiva

47. SCANLON, Geraldine M. «La mujer y la instrucción pública...» Op. cit., pp. 198-199.

48. SANFEliu, Luz. Republicanas. Identidades de género en el blasquismo (1895-1910). Valencia Universitat de València, 2005 y ÁlvareZ, Junco, José. El Emperador del Paralelo. Lerroux y la demagogia populista. Madrid, Alianza, 1990.

49. LÁzaro Lorente, Luis M. Las Escuelas Racionalistas en el País Valenciano (1906-1931). València, Universitat de València, 1992. 
Femenina en Málaga (1900-1907). ${ }^{50}$ Estas redes de feministas republicanas se constituyeron en una primera instancia para difundir entre las mujeres las ideas laicas y del librepensamiento y también para reclamar un cambio en el sistema educativo que diera a la población femenina posibilidades de acceder a la instrucción, incluida la superior. Lo característico de este nuevo feminismo fue su carácter eminentemente organizado y vinculado a la política y el hecho de que amplió el campo de sus actuaciones centrándose mayoritariamente en cuatro frentes: el escolar, el periodístico, el pacifista y el cívico secularizador. ${ }^{51}$

El núcleo catalán, liderado por la republicana Ángeles López de Ayala, editó El Progreso para difundir ideas seculares y emancipadoras ya que, desde su perspectiva, sin la «instrucción y redención de la mujer» nunca se culminaría en la sociedad la obra de la regeneración. Para desarrollar esta tarea dirigieron a lo largo del tiempo otras publicaciones como La Luz del Porvenir, El Gladiador en 1906, El Libertador en 1910 o El Gladiador del Librepensamiento en 1914..$^{52}$ En Valencia, la Asociación General Femenina publicó en $1896 \mathrm{La}$ Conciencia Libre que en 1900, cuando ya se editaba en Málaga, se definía como «una escuela de libertad y fraternidad»..$^{53}$

Esta nueva generación de feministas republicanas abrió también colegios femeninos como El Fomento de la Instrucción Libre de Barcelona, que entre 1891 y 1892 contaba con clases para niñas y adultas. Las obreras solían acudir a las clases nocturnas que eran gratuitas. Esta labor educativa se completó con conferencias quincenales sobre política para que «las asociadas conozcan todas las formas de gobierno, todas las religiones positivas $[\ldots] » .^{54}$ De forma similar, en Valencia la Asociación General Femenina puso también en funcionamiento una escuela nocturna para adultas y una escuela laica para niñas. ${ }^{55}$ La escuela de niñas, en torno a 1902, se amplió con otra dedicada a los niños. La Asociación hacía constar en sus estatutos que sus objetivos eran «la

50. Véase al respecto, RAmOS, $\mathrm{M}^{\mathrm{a}}$ Dolores. «La república de las librepensadoras (18901914): laicismo, emancipismo, anticlericalismo». Ayer, 60 (2005), pp. 45-74; «Hermanas en creencias, hermanas de lucha. Mujeres racionalistas, cultura republicana y sociedad civil en la Restauración». Arenal, 2 (julio-diciembre 2004), pp. 27-56.

51. RAmOS, $\mathrm{M}^{\mathrm{a}}$ Dolores. «Hermanas en creencias...» Op. cit., p. 30.

52. RAMOS, $\mathrm{M}^{\mathrm{a}}$ Dolores. «La república de las librepensadoras...» Op. cit., pp. 45-74.

53. El Pueblo, 13 de julio de 1896.

54. Las Dominicales del Librepensamiento, 30 de junio de 1898. Citado por RAMOS, Ma Dolores. «Hermanas en creencias...» Op. cit., p. 37.

55. El Pueblo, 11 de julio de 1897.

Feminismo/s 16, diciembre 2010, pp. 83-105 
propagación entre las mujeres de la instrucción, á fin de hacerla apta para el ejercicio de los derechos que le corresponden». ${ }^{56}$

Las mujeres más activas pertenecientes a estas redes feministas, como Ángeles López de Ayala, Belén Sárraga, Amalia y Ana Carvia Bernat o María Marín, que en algunos casos fueron maestras laicas, escribieron en la prensa republicana y librepensadora, subieron a las tribunas, encabezaron manifestaciones de mujeres o participaron como reconocidas figuras en señalados actos públicos. Con ello, las militantes en el asociacionismo feminista y librepensador exhibieron identidades femeninas en gran medida politizadas y autónomas, manifestando superar las atribuciones de género previstas para las mujeres de su tiempo. En pocos años, a sus demandas de una educación moderna y racional para las mujeres sumaron las reclamaciones al Estado de nuevos derechos civiles y políticos para la población femenina. También suscribieron contactos y alianzas con otros feminismos progresistas para incrementar su acción social. De igual modo, tanto en el partido socialista como en los partidos católicos y conservadores se organizaron agrupaciones femeninas que multiplicaron los aprendizajes informales de las mujeres en los ámbitos de la política.

En los años previos a la Primera Guerra Mundial, los horizontes laborales y educativos variaron discretamente para la población femenina. En 1910, la legislación eliminó las trabas para el ingreso de las mujeres en la universidad y el reconocimiento oficial de los títulos obtenidos facultó a las jóvenes de clases medias, al menos teóricamente, para el ejercicio de profesiones liberales. Asimismo, el Estatuto de Funcionarios de 1918 les permitió acceder al empleo en la Administración Pública. ${ }^{57}$ Las ya consolidadas Escuelas Normales ampliaron también su radio de acción con la creación de la Escuela Superior del Magisterio que se nutrió de futuras maestras que se caracterizaron no sólo por implementar nuevas teorías y prácticas educativas, sino también por ostentar maneras modernas de vivir de una forma independiente que las convertía en modelos para el conjunto de las mujeres. ${ }^{58}$

Otras maestras, como Benita Asas Manterola o Julia Peguero, constituyeron paralelamente la cantera de militantes de la Asociación Nacional de Mujeres Españolas (ANME) fundada en 1918. En dicha asociación se integrarían

56. Documentación del Colegio de niños y niñas de la Asociación Femenina. Archivo de la Universitat de València. Escuelas Privadas. Legajo 140-268.

57. AguAdo, Ana y Ramos, Ma Dolores. La modernización de España (1917-1939). Madrid, Síntesis, 2002, pp. 114-116.

58. Agulló DíAZ, $\mathrm{M}^{\mathrm{a}}$ del Carmen. Maestres valencianes republicanes. València, Universitat de València, 2008, pp. 20-22. 
progresivamente un grupo heterogéneo de mujeres de clases medias, maestras, escritoras y profesionales liberales vinculadas a partidos políticos de la izquierda española entre las que destacaron Clara Campoamor, María de Maeztu, Victoria Kent o la doctora Elisa Soriano. Entre sus objetivos, destacó la creación de la Juventud Universitaria Feminista que sumó al feminismo a una nueva generación de jóvenes estudiantes muy preparadas intelectualmente..$^{59}$

Este ambiente proclive al desarrollo de la instrucción y a la modernización de las conductas y de las mentalidades femeninas, sobre todo entre las clases medias urbanas, propició también que el histórico feminismo laicista se refundara en Valencia en 1915 a través de la revista Redención. ${ }^{60}$ Pocos años después, en 1918, distintas organizaciones feministas y republicanas repartidas por el Estado español coordinaron su esfuerzo a través de la Liga Española para el Progreso de la Mujer con la intención de reivindicar conjuntamente el derecho femenino al voto. Las alianzas de la Liga se ampliaron proyectando con la ANME una organización denominada Consejo Supremo Feminista, cuyo objetivo fue también vindicar derechos civiles y políticos.

Otras conocidas maestras, periodistas, literatas y feministas, como Carmen de Burgos o María Lejarraga, relacionadas también con el republicanismo y el socialismo, siguieron trayectorias semejantes. Presidieron minoritarias pero influyentes organizaciones feministas como la Cruzada de Mujeres Españolas o la Unión de Mujeres de España, reclamaron en sus ensayos, en la prensa o en las tribunas la modificación de los marcos legislativos en clave igualitaria y, a la altura de 1920, se mostraron abiertamente partidarias del voto.

Por esas fechas, la evolución del sistema educativo estaba haciendo posible que la escolarización primaria fuese prácticamente equivalente para ambos sexos. En los años 1916-1917 había un 51.0\% de niños escolarizados frente a un $49.0 \%$ de niñas. En el bachiller sin embargo, el alumnado femenino alcanzaba en 1919 la exigua cifra del $8.40 \%$ y el de la Universidad del $1.5 \% .{ }^{61}$ Tal vez por ello, las metas del minoritario feminismo hispano se centraron en apoyar y hacer visible nuevos modelos identitarios que abundaban en la profesionalización femenina, en la vinculación de la mujeres con los partidos políticos y en la consecución de una ciudadanía plena.

Con la creación en 1926 del Lyceum Club emergió en la esfera pública un nutrido grupo de mujeres de reconocido prestigio: profesoras, médicas, traductoras, farmacéuticas, abogadas, periodistas, dibujantes, psicólogas,

59. FAGOAGA, Concha. La voz y el voto de las mujeres El sufragismo en España 1877-1931. Barcelona, Icaria, 1985, pp. 129-132.

60. Ibíd., p. 135.

61. Ballarín Domingo, Pilar. La Educación de las mujeres... Op. cit., p. 91.

Feminismo/s 16, diciembre 2010, pp. 83-105 
literatas o artistas. El Lyceum estaba constituido como un centro cultural a modo de plataforma pública de la emancipación femenina y la mayoría de integrantes de la ANME militaron en el mismo. ${ }^{62}$ Además de desarrollar una extensa vida artística y cultural, en sus salones se gestionó la campaña de 1927 para suprimir el artículo 57 del código civil que obligaba a la mujer a acatar lo que dijese el marido y se pidió la derogación del artículo 438 que trataba sobre el castigo que recibía una esposa infiel. Como parte de la campaña se defendió además la igualdad económica entre esposa y marido y se luchó por conseguir el voto femenino. ${ }^{63}$ En todo caso, las mujeres que asistieron al Lyceum, activas en la vida pública y más libres en sus atribuciones de género, dada en gran medida su condición de profesionales, eran tachadas por la prensa editada por la derecha reaccionaria de «ateas» $\mathrm{O}$ «desertoras del hogar». ${ }^{64}$

Nuevos y más amplios ámbitos de actuación y una sociabilidad democrática gestionada por las propias mujeres continuaban ensanchando el campo de su acción social y consolidando nuevas formas de identidades femeninas que seguían acortando los márgenes de la complementariedad entre los géneros y de la diferencia sexual.

\section{Epílogo}

Como afirma Foucault, donde hay poder hay resistencias y las resistencias no pueden existir más que en una multiplicidad de puntos que conforman una red de relaciones que posibilita que el poder circule por el entramado social. ${ }^{65}$ En un proceso de larga duración, las «redes de resistencia» cuyos discursos y prácticas abogaban por la educación de las mujeres ensancharon las fronteras de la autonomía femenina, lo que contribuyó a modificar su subjetividad. En el entramado social se trazaron alianzas y negociaciones entre grupos afines que modificaron socialmente la idea de la «evidente» inferioridad intelectual de las mujeres e implicaron al Estado y a la sociedad en la tarea de reglamentar e institucionalizar espacios educativos y profesionales que les posibilitaran desarrollar su individualidad «más allá del hogar».

Ya en la II República, las redes de relaciones que hacen factible que el poder circule y que se modifiquen subjetividades y atribuciones sociales habían logrado dotar de cierta autoridad en los escenarios públicos a una élite

62. BAROJA NESSI, Carmen (A. Hurtado ed.). Recuerdos de una mujer de la Generación del 98. Barcelona, Tusquets, 1998, pp. 26-27.

63. Ibíd., p. 29.

64. MANGINI, Shirley. Las modernas de Madrid. Las grandes intelectuales españolas de la vanguardia. Barcelona, Península, 2001, p. 90.

65. Foucault, Michel. Historia de la sexualidad... Op. Cit., p. 116. 
intelectual femenina rectora del proceso emancipador. Fueron mujeres que se caracterizaron por su preparación intelectual, por su prestigio profesional, por su militancia política y por su compromiso con la causa feminista, lo que las llevó a desempeñar un importante papel político y cultural en su época. A lo largo del tiempo, esas redes de relaciones que difundieron posibilidades alternativas con respecto a las atribuciones de la feminidad habían operado cambios en espacios institucionales, legislativos, pedagógicos, educativos o socio-políticos que en última instancia significaron cambios en la representación de poder.

Finalmente, las reformas emprendidas por el gobierno provisional y la Constitución democrática de 1931 eliminaron parcialmente la tradicional subordinación femenina con la introducción en el texto de cambios legislativos que hacían realidad la ciudadanía femenina en clave igualitaria.

\section{Referencias bibliográficas}

Aguado, Ana (coord.). Dossier; Culturas Políticas y Feminismos. Historia Social. 67 (2010), pp. 69-173.

AguAdo, Ana y RAMOS, Mª Dolores. La modernización de España (1917-1939). Madrid, Síntesis, 2002.

AGulló DíAZ, $\mathrm{M}^{\mathrm{a}}$ del Carmen. Mestres valencianes republicanes. València, Universitat de València, 2008.

Álvarez Junco, José. El Emperador del Paralelo. Lerroux y la demagogia populista, Madrid, Alianza, 1990.

Amorós, Celia. Tiempos de feminismo. Sobre feminismo, proyecto ilustrado y postmodernidad. Madrid, Cátedra, 1997.

ANDERSON, Benedict. Comunidades imaginadas. Reflexiones sobre el origen y la difusión del nacionalismo. México, Fondo de Cultura Económica, 1993.

BALLARÍN DOMINGO, Pilar. La Educación de las mujeres en la España contemporánea (siglos XIX y XX). Madrid, Síntesis, 2001.

- «La construcción de un modelo educativo de <<utilidad doméstica»>». En G. Fraisse y M. Perrot (dir.). Historia de las mujeres. El siglo XIX. Madrid, Taurus, 1993, pp. 599-611.

BAROJA NESSI, Carmen (A. Hurtado ed.). Recuerdos de una mujer de la Generación del 98. Tusquets, Barcelona, 1998.

Bourdieu, Pierre y PASSERON, Jean-Claude. La Réproduction: éléments pour une théorie du système d'enseignement. París, Les Editions de Minuit, 1970.

CABRERA BOCH, Isabel. «Ciudadanía y género en el liberalismo decimonónico español». En P. Pérez Cantó (ed.). También somos ciudadanas. Madrid, Universidad Autónoma de Madrid, 2000, pp. 171-214. 
CAPEl Martínez, Rosa $\mathrm{M}^{\mathrm{a}}$. «La apertura del horizonte cultural femenino: Fernando de Castro y los Congresos Pedagógicos del siglo XIX». En Ma Á. Duran [et al.] (eds.). Mujeres y sociedad en España, 1700-1975. Madrid, Ministerio de Cultura, Instituto de la Mujer, 1986, pp. 109- 145.

Cuesta EsCudero, Pedro. La Escuela en la reestructuración de la Sociedad Española. 1900-1923. Madrid, Siglo XXI, 1994.

De la Fuente Monge, Gregorio y Serrano García, Rafael. La revolución gloriosa. Un ensayo de regeneración nacional. Antología de textos. Madrid, Biblioteca Nueva, 2005.

Di FEBO, Giuliana. «Orígenes del debate feminista en España. La Escuela krausista y la Institución Libre de Enseñanza (1870-1890)». Sistema, 12 (1976), pp. 49-82.

ESPIGADO, Gloria. «Las mujeres en el nuevo marco político». En I. Morant (dir.). Historia de las Mujeres en España y América Latina. Del siglo XIX a los umbrales del XX. Madrid, Cátedra, pp. 27-60.

FAGOAGA, Concha. La voz y el voto de las mujeres El sufragismo en España 18771931, Barcelona, Icaria, 1985.

Foucault, Michel. Historia de la sexualidad: la voluntad de saber. Madrid, Siglo XXI, 1976.

— «El sujeto y el poder». En H. Dreyfus y P. Rabinisu (coords.). Michel Foucault: más allá del estructuralismo y la hermenéutica. México, Universidad de México, 1988.

Gil de Zárate, Antonio. De la Instrucción Pública en España, Colegio de SordoMudos, 1855. (Edición facsímil, Pentalfa, Oviedo, 1995, tomo 1).

HoBSBAWM, Eric. La era del capitalismo (1848-1875). Madrid, Guadarrama, 1977.

MANGINI, Shirley. Las modernas de Madrid. Las grandes intelectuales españolas de la vanguardia. Barcelona, Península, 2001.

LÁzAro Lorente, Luis M. Las Escuelas Racionalistas en el País Valenciano (19061931). València, Universitat de València, 1992.

MARTínEz, Cándida [et al.] (dirs.). Mujeres en la Historia de España. Enciclopedia biográfica. Barcelona, Planeta, 2000.

OSSENBACH SAUTER, Gabriela. «Génesis de los sistemas educativos nacionales en Mundo Occidental». En A. Tiana Ferrer [et al.] (coords.). Historia de la Educación. Edad Contemporánea. Madrid, 2002, UNED, pp. 21-38.

PALACIOS LIS, Irene. «Mujeres aleccionando a mujeres. Discursos sobre la maternidad en el siglo XIX». Historia de la educación, 26 (2007), pp. 111-142.

PEÑARRUBIA, Isabel. Entre la ploma i la tribuna, Els orígens del primer feminisme a Mallorca, 1869-1890. Barcelona, Publicacions de l'Abadia de Montserrat, 2006.

Pirala, Antonio. El libro de oro de las niñas. Madrid, Establecimiento tipográfico de Mellado, 1860. 
RAmos, Mª Dolores. «La república de las librepensadoras (1890-1914): laicismo, emancipismo, anticlericalismo». Ayer, 60 (2005), pp. 45-74.

- «Hermanas en creencias, hermanas de lucha. Mujeres racionalistas, cultura republicana y sociedad civil en la Restauración». Arenal, 2 (julio-diciembre 2004), pp. 27-56.

Rebollo EsPinosa, María José y NúÑEz GIL, Marina. «Tradicionales, rebeldes, precursoras: instrucción y educación e las mujeres españolas a través de la prensa femenina (1900-1970)». Historia de la educación, 26 (2007), pp. 181-219.

RODRÍGUEZ SÁNCHEZ, Ma de los Ángeles. «Matilde Cherner y «La Ilustración de la Mujer»». En L.F. Díaz Larios [et al.] (eds.). Lectora, Heroína, Autora (La mujer en la literatura española del siglo XIX). III Coloquio de la Sociedad de Literatura Española del Siglo XIX (Barcelona, 23-25 de octubre de 2002). Barcelona, 2005, pp. 307-319.

SAiz Otero, Concepción (C. Colmenar Orases ed.). La revolución del 68 y la cultura femenina. Un episodio nacional que no escribió Pérez Galdós. Madrid, Biblioteca Nueva, 2006.

SANFEliU, Luz. Republicanas. Identidades de género en el blasquismo (1895-1910). Valencia, Universitat de València, 2005.

— «Republicanismo y ciudadanía femenina en el Sexenio democrático». Bulletin d histoire contemporaine de l'Espagne, 46 (2009) (en prensa).

SARASÚA GARCía, Carmen. "El acceso de niñas y niños a los recursos educativos de la España rural del siglo XIX». En J. M. Martínez Carrión (ed.). El nivel de vida en la España rural de los siglos XVII-XX. Alicante, Universidad de Alicante, 2002, pp. 415-463.

SCANLON, Geraldine M. La polémica Feminista en la España contemporánea. (18681971). Madrid, Siglo XXI, 1976.

— «La mujer y la instrucción pública: De la Ley Moyano a la II. ${ }^{a}$ República». Historia de la Educación, 6 (1987), pp. 193-207.

ScotT, Joan W. «El género; una categoría útil para el análisis histórico». En J. S. Amelang y M. Nash (eds.). Historia y Género: Las mujeres en la Europa Moderna y Contemporánea. Valencia, Alfons el Magnànim, 1990, pp. 23-56.

TURIN, Yvonne. La educación y la escuela en España de 1874 a 1902. Madrid, Aguilar, 1967. 